
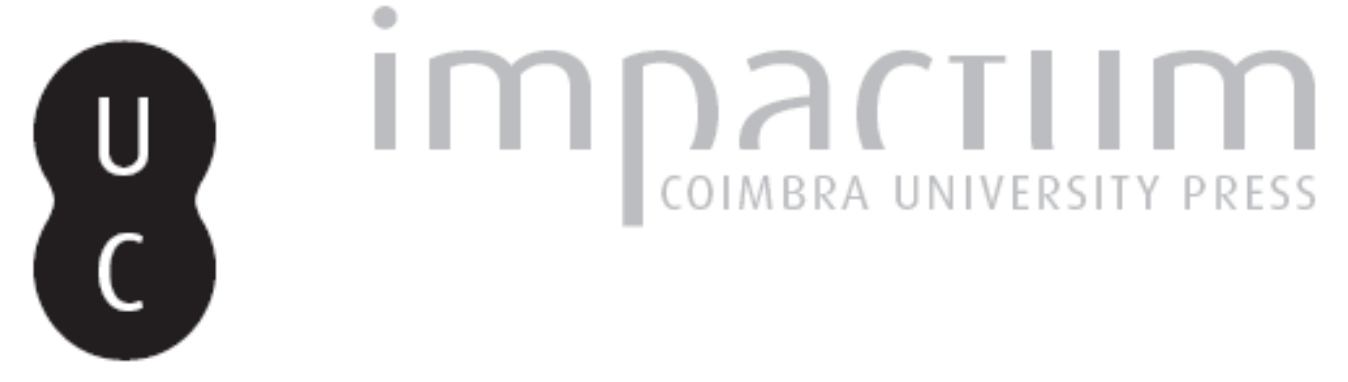

\title{
Risco de ignição de incêndios florestais associado à circulação de material ferroviário em linhas de caminho de ferro
}

Autor(es): $\quad$ Lourenço, Luciano; Rocha, João

Publicado por: Associação Portuguesa de Riscos, Prevenção e Segurança

URL persistente:

URI:http://hdl.handle.net/10316.2/36096

DOI:

DOI:http://dx.doi.org/10.14195/1647-7723_17_7

Accessed : $\quad$ 26-Apr-2023 15:35:17

A navegação consulta e descarregamento dos títulos inseridos nas Bibliotecas Digitais UC Digitalis, UC Pombalina e UC Impactum, pressupõem a aceitação plena e sem reservas dos Termos e Condições de Uso destas Bibliotecas Digitais, disponíveis em https://digitalis.uc.pt/pt-pt/termos.

Conforme exposto nos referidos Termos e Condições de Uso, o descarregamento de títulos de acesso restrito requer uma licença válida de autorização devendo o utilizador aceder ao(s) documento(s) a partir de um endereço de IP da instituição detentora da supramencionada licença.

Ao utilizador é apenas permitido o descarregamento para uso pessoal, pelo que o emprego do(s) título(s) descarregado(s) para outro fim, designadamente comercial, carece de autorização do respetivo autor ou editor da obra.

Na medida em que todas as obras da UC Digitalis se encontram protegidas pelo Código do Direito de Autor e Direitos Conexos e demais legislação aplicável, toda a cópia, parcial ou total, deste documento, nos casos em que é legalmente admitida, deverá conter ou fazer-se acompanhar por este aviso.

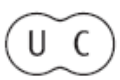




\section{territorium}

Riscos, Sociedade(s) e Segurança

Revista da Associação Portuguesa de Riscos, Prevenção e Segurança 2010 

CAMINHO DE FERRO ${ }^{1 *}$

\author{
Luciano Lourenço \\ Departamento de Geografia da Faculdade de Letras da Universidade de Coimbra \\ luciano@uc.pt \\ João Rocha \\ NICIF - Núcleo de Investigação Científica de Incêndios Florestais \\ joaorocha@nicif.pt
}

\title{
RESUMO
}

Os incêndios florestais, motivados por causas antrópicas e naturais, constituem, na actualidade, a principal ameaça à floresta portuguesa. Por sua vez, as causas acidentais, que estão na origem de muitos deles, correspondem a um cluster específico em termos das suas causas.

Os incêndios florestais nas imediações e/ou contiguidade da linha de caminho de ferro apresentam um valor relativamente reduzido no contexto geral dos incêndios em Portugal. No entanto, no conjunto das causas acidentais, revelam um quantitativo relativamente significativo, com consequências nos totais de área ardida e, sobretudo, na operacionalidade e interrupção temporária da circulação de composições ferroviárias.

Palavras-chave: risco de ignição, circulação ferroviária, linha de caminho de ferro, incêndio florestal, prevenção.

\section{RÉSUMÉ}

Les incendies de forêt, grâce à des causes anthropiques et naturelles, sont, à l'heure actuelle, la principale menace pour les forêts portugaises. En retour, les causes accidentelles, qui sont la source de beaucoup d'entre eux, correspondent à un groupe particulier en termes de leurs causes.

Les incendies de forêt dans le voisinage et/ou dans la proximité de la ligne de chemin de fer ont une valeur relativement faible dans le contexte général des incendies au Portugal. Toutefois, dans toutes les causes accidentelles, montrent une quantité relativement importante, avec des implications pour la superficie totale brûlée, et surtout dans l'exploitation et l'interruption de la circulation des trains.

Mots-clé: risque d'inflammation, trafic ferroviaire, chemins de fer, incendies de forêt, prévention.

\section{ABSTRACT}

Forest fires, caused by anthropogenic and natural causes, are, at present, the main threat to the Portuguese forest. In turn, the accidental causes, which are the source of many of them, correspond to a particular cluster in terms of their causes.

Forest fires in the vicinity and/or adjacent to the railway line have a relatively low value in the general context of the fires in Portugal. However, in all accidental causes, show a quantitatively large, with implications for the total area burned, and especially in the operation and interruption of the movement of trains.

Key words: risk of ignition, rail traffic, railway line, forest fire, prevention.

$1^{*} \mathrm{O}$ texto deste artigo corresponde à comunicação apresentada ao V Encontro Nacional e I Congresso Internacional de Riscos e foi submetido para revisão em 28-05-2009, tendo sido aceite para publicação em 02-03-2010.

Este artigo é parte integrante da Revista Territorium, n. ${ }^{\circ} 17,2010$, (c) Riscos, ISBN: 0872- 8941. 


\section{Introdução}

0 trabalho que se apresenta teve como objectivos principais: tipificar os vários focos de incêndio florestal com origem, provável, na circulação de comboios; apurar a importância das ignições com origem nas linhas de caminho de ferro; caracterizar as circunstâncias propícias à ignição de incêndios e identificar as ferrovias prioritárias para intervenção preventiva.

Para o efeito, caracterizaram-se as linhas de caminhode-ferro mais críticas em matéria de ocorrência de incêndios florestais e estabeleceu-se a relação dessas com as possíveis causas de ignição, com o objectivo de detectar eventuais relações de causa/efeito.

De igual modo, pretendeu-se avaliar de que forma é que a circulação de comboios poderia estar na origem de determinados focos de incêndios, alguns dos quais com consequências relevantes no que concerne às áreas ardidas resultantes.

O estudo teve como referência o período compreendido entre 2002 e 2008, tendo sido estruturado com uma metodologia que se centrou fundamentalmente em três etapas: a primeira consistiu na análise e tentativa de uniformização dos dados provenientes de diferentes entidades; a segunda permitiu a realização de trabalho de campo nas áreas consideradas mais propensas ao risco de ignição e, na última, procedeu-se à sistematização da informação recolhida e à elaboração de cartografia de pormenor.

Assim, a partir da informação disponível identificaramse, numa primeira fase, as linhas de caminho-deferro mais críticas em matéria de incêndios florestais e, posteriormente, caracterizaram-se, de forma sistemática, as circunstâncias potenciadoras de ignições.

A realização deste estudo baseou-se na análise de informações estatísticas, as quais permitiram constituir uma base de dados, em que foram sistematizadas as diversas fontes de informação, com o objectivo de estabelecer um padrão de dados face a todas as situações relatadas.

Assim, a uniformização da informação apoiou-se nas seguintes fontes de informação:

- Ponto de situação dos registos dos incêndios florestais (código 212), Autoridade Florestal Nacional (AFN);

- Registo de Ocorrências, CP/REFER;

- Autos de Notícia (Ficha de determinação das causas - parte técnica), GNR/SEPNA;

- RISCOS - Trabalho de campo.

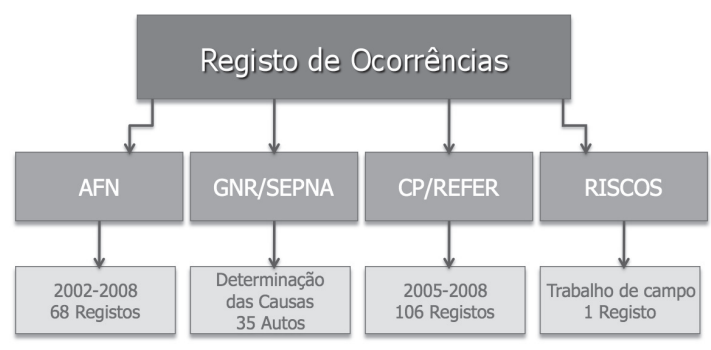

Fig. 1 - Distribuição dos registos por fonte.

Numa primeira etapa, a análise destes registos e, em particular, dos autos de notícia permitiu contextualizar as diversas situações, tendo-se criado uma base de dados na qual constavam todas as informações descritas nesses registos e autos.

Posteriormente, toda a informação alfanumérica disponível foi sujeita a um processo de normalização e de controlo de qualidade, uma vez que alguns dos registos estavam parcialmente preenchidos o que poderia de algum modo desencadear situações de analise incorrecta e erros de interpretação.

\section{Elementos estatísticos e a sua não uniformização}

O tratamento da informação estatística disponibilizada revelou-se como a principal forma de abordagem para a compreensão da evolução histórica da problemática.

Com efeito, para o período em análise, consideraram-se apenas 97 ocorrências de incêndio florestal, com origem provável no caminho-de-ferro (causa 212), no conjunto dos 165 registos. Durante o processo de verificação, foi possível detectar as ignições que ainda não constavam do registo oficial, confrontando os 68 registos de incêndios florestais recebidos da AFN, com os 35 autos de notícia provenientes da GNR.

Por sua vez, os 106 registos disponibilizados pela CP/ REFER, referentes, apenas, aos anos de 2006 a 2008, permitiram constatar a existência de 23 ignições não constantes das estatísticas oficiais (AFN). Por sua vez, o trabalho de campo permitiu assinalar mais uma ocorrência em 2008, de acordo com informação fornecida pelo Corpo de Bombeiros de Pinhel, ao tempo também inédita, pois não constava de nenhuma das três fontes de informação antes mencionadas (fig.2).

Apesar de, por vezes, estes registos se encontrarem incompletos e com formas de preenchimento não uniformizadas, possibilitaram a sistematização dos dados e a análise de alguns dos factos relacionados com as ignições.

Com efeito, se alguns dos autos disponibilizados pela GNR descrevem as ocorrências de forma exaustiva e completa, fornecendo dados relativos às condições 


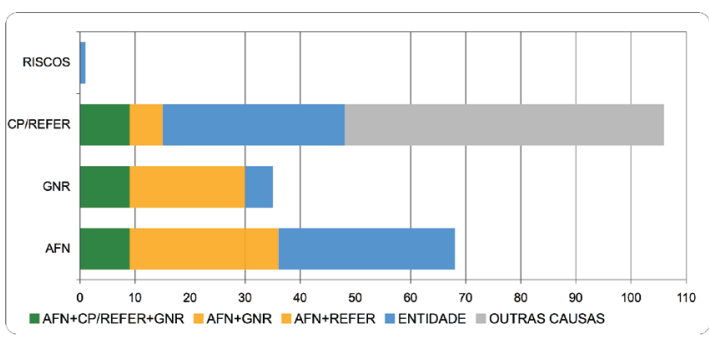

Fig. 2 - Distribuição do número de ocorrências (causa 212) pelas respectivas fontes de informação.

atmosféricas, características geográficas, tipologia de uso e de ocupação do solo, áreas e pessoas afectadas, presença de testemunhas e de provas circunstanciais, reconstituição e descrição dos factos, croquis (apoiados nas respectivas cartas militares), fotografias, etc., outros há, contudo, em que a informação disponível é bastante diminuta e pouco objectiva.

De facto, a discrepância existente entre os diferentes tipos de informação relativa às ocorrências, foi uma das maiores contrariedades encontradas para o seu tratamento uniforme, tanto mais que alguns desses dados carecem de referenciação geográfica, além de que, por vezes, não possuem qualquer informação alfanumérica associada.

Identificação das linhas de caminho-de-ferro mais críticas em matéria de incêndios florestais (2002 - 2008)

A evolução da actividade ferroviária, com a passagem das locomotivas a vapor para diesel e, posteriormente, para as composições eléctricas, teve resultados na diminuição de situações potenciais de risco de ignições motivadas pela libertação de material incandescente proveniente dos sistema de combustão e de escape ao longo das linhas de caminho-de-ferro.

Em Portugal, as composições movidas a vapor operam, maioritariamente, nas linhas do Douro e do Corgo, sendo constituídas por locomotivas históricas, cuja finalidade é exclusivamente turística. No entanto, os registos de ignições remetem para situações ocorridas em linhas e ramais com trafego ferroviário por tudo o pais.

Em termos de causualidade as ignições podem, eventualmente, ter origem em partículas (faúlhas) provenientes dos sistema de combustão das locomotivas (tracção a diesel ou a vapor), automotoras (tracção a diesel), veículos (dresinas) e veículos afectos a trabalhos de via (REFER, 2009). Esta causualidade pode estar associada aos sistemas de combustão e escape mas também, e, principalmente, aos sistemas de frenagem, constituídos pelos rodados e cepos de freio que, sujeitos a elevado aquecimento, são passíveis de libertarem fragmentos metálicos incandescentes. Por outro lado, as situações de operacionalização de maquinaria de tração e os trabalhos de manutenção das vias, também podem constituir fonte de ignição a ter em conta (DFFP, 1999).

Incêndios florestais nas imediações e/ou contiguidade da via férrea - Evolução 1991-2007

As linhas férreas são afectadas por incêndios florestais nas suas imediações e/ou contiguidade que, mesmo quando têm origem exógena a essa estrutura ferroviária, acabam por afectar e perturbar o normal funcionamento da circulação. Por sua vez, quando são endógenas podem afectar a circulação ferroviária e, causar danos relevantes nas áreas agrícolas/florestais adjacentes à via férrea. Esta situação além de acarretar prejuízos para a CP/REFER, poderia muitas vezes ser evitada se, junto à via, fosse mantida uma adequada gestão dos combustíveis.

De acordo com os relatórios anuais sobre incêndios florestais elaborados pela $\mathrm{CP} / \mathrm{REFER}$, a evolução do número de ocorrências de incêndio a nível nacional, no período compreendido entre 1991 e 2007, comparativamente com as ocorrências de incêndio com incidência nas vias férreas, independentemente da sua origem endógena ou exógena, mostra que não é possível estabelecer uma relação directa entre ambas (CP/REFER, 2006).

É possível verificar uma certa correlação entre alguns dos anos em que, simultaneamente, se registou um maior número de ocorrências, quer em termos nacionais, quer na afectação de caminhos-de-ferro, como sucedeu em 1995 e 2000, mas tal já não é válido para outros anos, como, por exemplo, os de 1996 e 1998 (CP/REFER, 2005).

Por sua vez, os anos de 1992 e 2007 registaram, proporcionalmente, um maior número de ocorrências a afectar a rede ferroviária do que espaços florestais, pelo que, deste modo, não se pode estabelecer uma relação directa entre o número de ignições nas vias férreas e o número de ocorrências registadas no território continental (CP/REFER, 2007).

\section{Distribuição temporal das ocorrências}

Tendo por base os dados estatísticos coligidos para o período compreendido entre 2002 e 2008, por serem os anos para os quais foi possível reunir informação com o nível de detalhe, procedeu-se à análise dos valores referentes ao número de ocorrências e às áreas ardidas, distribuídos por ano, mês, hora e duração. Convém assinalar que apenas foram consideradas as ocorrências de incêndio florestal com causa provável nas linhas de caminho-de-ferro.

Aárea ardida em 2007 e 2008 (fig. 3) é consideravelmente diminuta, face ao elevado número de ocorrências registado, sobretudo quando comparada com a observada 
nos anos de 2003 e 2004, respectivamente, com 47,2\% e $36,7 \%$ do valor total. No entanto, é de referir que, para o ano de 2008, não existe informação sobre a área ardida em 18 ocorrências da CP/REFER, das 47 registadas.

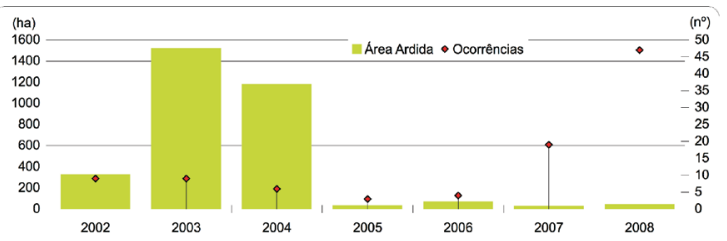

Fig. 3 - Distribuição anual do número de ocorrências e da área ardida, entre 2002 e 2008.

Em termos globais, o ano menos gravoso (2005), registou apenas três ocorrências e uma área ardida inferior a 35 ha, ao contrário do que sucedeu a nível nacional, pois esse ano registou o maior número de ocorrências, desde que há registos sistemáticos (1980), mas também se posicionou em segundo lugar no que respeita ao total da área ardida.

A análise mensal do número de ocorrências (fig.4), permite verificar que são os meses de Julho, Junho e Agosto aqueles que registaram o maior número de ocorrências, respectivamente, 36 (37,1\%), 17 (17,5\%) e $16(16,5 \%)$ ignições. De destacar, ainda, nove ocorrências $(9,3 \%)$, verificadas nos meses de Março e Setembro e uma (1\%) ocorrida no mês de Fevereiro com carácter excepcional.

No que concerne aos quantitativos de área ardida o mês de Julho regista o valor mais elevado com um total de 2442 ha (75,8\%). A restante área ardida (780 ha), está repartida maioritariamente pelos meses de Junho e Setembro, com $15,4 \%$ e $6,6 \%$, respectivamente.

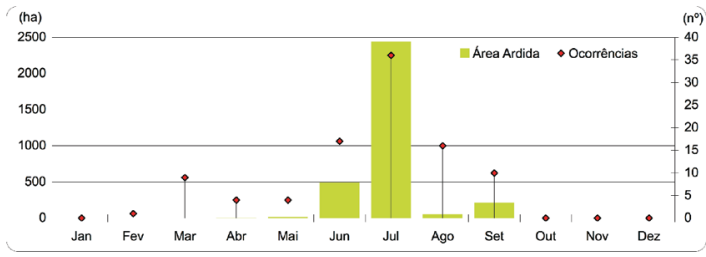

Fig. 4 - Distribuição mensal das ocorrências e da área ardida, entre 2002 e 2008.

0 mês de Agosto, que em termos médios regista valores médios de temperatura mais elevados e humidade relativa do ar mais reduzidos, detém $1,7 \%$ do total de área ardida. Esta situação poderá estar, eventualmente, relacionada com o período de férias e a consequente diminuição do tráfego de composições de carga/ mercadorias.

A distribuição em termos horários, permite verificar que, para o período estudado, as ignições deflagraram entre as 8:00 da manhã e as 22:00 da noite. Sendo que, cerca de $60 \%$ das ignições foram comunicadas entre as 13:00 e as 17:00 horas, com o maior número, 16 (21,6\%), a deflagrar entre as 14:00 e as 15:00 horas, seguindo-se o período das $13: 00$ às $14: 00$, no qual foram registadas 13 ocorrências, ou seja, $17,6 \%$ do total.

No que se refere à área ardida, cerca de $77 \%$, diz respeito a ocorrências cujo alerta foi dado entre as 13:00 e as 16:00 horas.

Por sua vez, a maior área ardida, 1325 ha (41,1\%), corresponde a ocorrências cujo alerta foi dado entre as 13:00 e as 14:00 horas, seguida pelo período compreendido entre as 15:00 e as 16:00 horas.

A duração de cada ocorrência diz respeito ao número de horas da respectiva intervenção, compreendido entre o momento de alerta e a desmobilização dos meios, incluindo, portanto, o tempo de rescaldo e de vigilância pós-incêndio. 0 valor quantificado peca por excesso, em termos de interrupção da circulação, pelo que tem, apenas, um valor indicativo, uma vez que não foi possível determinar o número de horas em que a circulação ferroviária esteve afectada.

Do total dos 97 registos estudados, não foi possível apurar a duração de 37 ocorrências $(38,1 \%)$. O somatório das restantes corresponde a um período de tempo de $307 \mathrm{~h}: 22 \mathrm{~m}$, ao longo do qual, directa ou indirectamente, a circulação ferroviária poderá ter estado afectada.

A análise estatística permitiu verificar que a maior parte das ocorrências (70\%) teve uma duração inferior a $6 \mathrm{~h}$ e, somente $13 \%$, tiveram duração inferior a $1 \mathrm{~h} .0$ valor mais elevado foi registado, em 2003, no Ramal de Cáceres, com uma duração de $48 \mathrm{~h}$ e $45 \mathrm{~m}$, com uma área ardida de 110 ha. No entanto, no que toca ao número de horas de intervenção no combate a incêndios florestais foi a Linha da Beira Alta aquela que registou o maior número de horas de intervenção, seguida pelo Ramal de Cáceres e Linha de Leste.

\section{Distribuição espacial das ocorrências}

A distribuição do número de ocorrências e das áreas ardidas, no contexto administrativo, permitiu verificar as assimetrias registadas ao nível dos distritos e concelhos, quer em termos ferroviários, por linhas e ramais.

No conjunto dos 151 concelhos atravessados por linhas e ramais, registaram-se, em 44 deles $(29,1 \%)$, ocorrências de incêndios florestais com origem provável na linha de caminho-de-ferro. Estes concelhos encontram-se distribuídos por 14 distritos, tendo sido o distrito da Guarda (fig.5) o que mais se destacou, quer pelo maior número de ocorrências, quer pelo maior quantitativo de área ardida. 


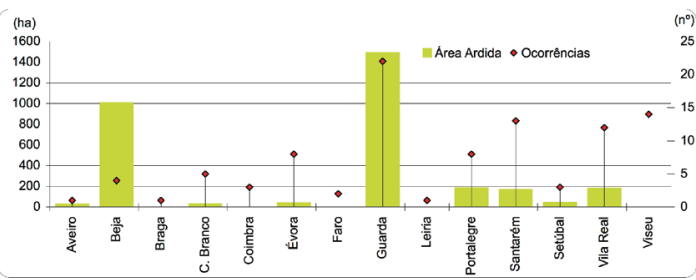

Fig. 5 - Distribuição distrital do número total de ocorrências e da área ardida, entre 2002 e 2008.

A nível concelhio destacam-se, em termos do número de ocorrências, os concelhos de Pinhel e de Celorico da Beira (distrito da Guarda), respectivamente com 9 e 8 ocorrências. Seguem-se os concelhos de Mangualde, do distrito de Viseu, e de Alijó, do distrito de Vila Real, ambos com 6 ocorrências.

No que respeita à área ardida, destaca-se o concelho de Celorico da Beira, com 1218 ha ardidos, dos quais, 1144 ha dizem respeito a um único incêndio registado no ano de 2004. Por sua vez, no ano anterior, de 2003, uma ocorrência teve como resultado 803 ha de área registada no concelho de Alvito, distrito de Beja.

A análise dos dados, distribuídos por linhas e ramais ferroviários, permitiu destacar a Linha da Beira Alta (fig.6), quer em termos de área ardida quer em termos de ocorrências. Esta linha, contribuiu com 38 ocorrências, ou seja, $39,2 \%$ do total, enquanto que, em termos de área ardida, registou 1499 ha, o que corresponde a $46,5 \%$ do total, pelo que não deixa de ser particularmente significativo, sobretudo tendo em conta que é esta Linha que assegura a maioria dos transportes ferroviários internacionais.

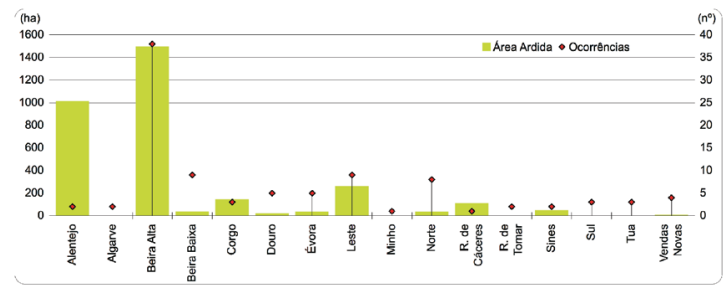

Fig. 6 - Distribuição do número de ocorrências e área ardida, entre 2002 e 2008, na rede ferroviária nacional.

A Linha do Alentejo destaca-se em termos de área ardida, tendo sido registadas duas ocorrências das quais resultaram 1000 ha, 31,4\% do total. Merecem, ainda, referência a Linha do Leste, com 264 ha $(8,2 \%)$ e a Linha do Corgo, com 144 ha (4,5\%).

No que diz respeito ao tipo de combustíveis afectados notaram-se algumas diferenças entre as linhas. Assim, na Linha da Beira Alta, a maior percentagem ardida coube aos matos, 954 ha $(63,7 \%)$, enquanto que na Linha do Alentejo, o maior valor da área ardida, 502 ha $(49,6 \%)$, corresponde a áreas ocupadas por espécies do estrato arbóreo (fig. 14) que, segundo informação retirada dos Autos de Notícia da GNR, são maioritariamente, constituídas por sobreiros e azinheiras.

Todavia, a área ardida em espaço agrícola, também assume algum significado nestas linhas, mas apenas, na da Beira Baixa, a totalidade da área ardida, 30 ha queimados em 2004, se reporta a campos agrícolas.

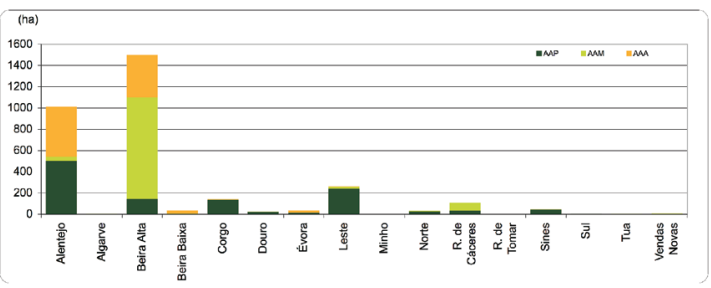

Fig. 7 - Distribuição da área ardida, entre 2002 e 2008, por linha e ramal ferroviário.

AAP - Área ardida em povoamentos florestais; AAM - idem, em mato; AAA - ib. em espaço agrícola.

Atendendo à dimensão média da área ardida por número de ocorrências, verifica-se que foi na Linha do Alentejo e no Ramal de Cáceres que se registaram os incêndios florestais com maior dimensão, respectivamente com 506 e 110 ha. Por sua vez, a Linha da Beira Alta, sendo aquela que regista a maior probabilidade de ocorrências, apresenta uma menor expressão face às anteriores no que concerne a dimensão da área ardida por ocorrência, apenas 45, 4 ha.

Voltando ao número das ocorrências, depois da Linha da Beira Alta e a uma distância considerável, surgem, em segundo lugar, as Linhas do Leste e da Beira Baixa, ambas com 9 ocorrências $(9,3 \%)$, seguidas pela Linha do Norte, com 8 ocorrências $(8,2 \%)$.

\section{Caracterização das circunstâncias em que ocorreram} as ignições (2002 - 2008)

A maioria das causas prováveis imputadas à via férrea parecem estar associadas a ignições originadas pela emissão de fragmentos incandescentes, faíscas e transmissão de calor decorrente de diversas actividades ferroviárias, designadamente a problemas relacionados com o sistema de frenagem do material circulante ou com a realização de trabalhos na via.

A comparação dos registos fornecidos pela CP/REFER com a informação proveniente das outras entidades relativa às ocorrências investigadas pela GNR e classificadas com a causa 212 permitiu tratar as ocorrências com incidência negativa na ferrovia, em termos de exploração ferroviária e de infra-estruturas.

Segundo a codificação de causas dos incêndios florestais em vigor (CNGF, 2003), as ocorrências relacionadas 


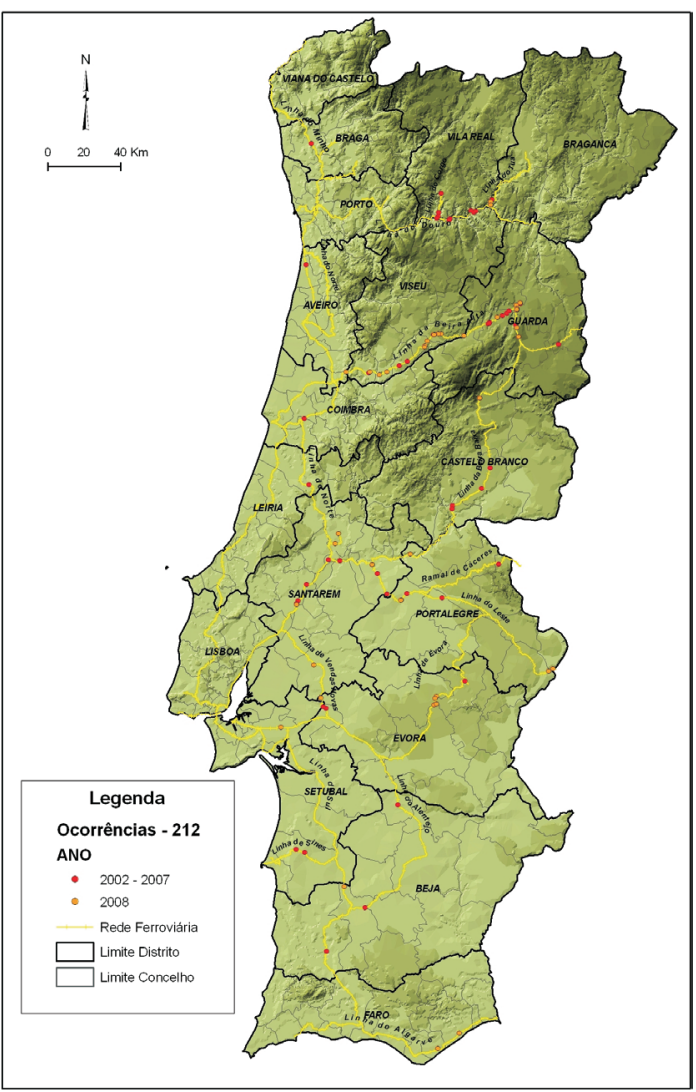

Fig. 8 - Distribuição geográfica do número das ocorrências, entre 2002 e 2008.

com o material incandescente proveniente do sistema de frenagem ou locomoção de transportes ferroviários, estão associadas à classe acidentais (código 2), subgrupo transportes e comunicações (código 21), causa caminhosde-ferro (Código 212) (Carvalho, 2003).

Por sua vez, as causas acidentais correspondem à segunda das seis categorias de causas de incêndios florestais. As causas acidentais analisadas (associadas aos transportes e comunicações) assumem alguma preponderância no conjunto das causas acidentais.

No que concerne ao subgrupo transportes e comunicações (código 21), verificou-se que os caminhos-de-ferro têm um peso importante neste tipo de causa, com especial relevância nos anos de 2002, 2003 e 2004 (fig. 9).

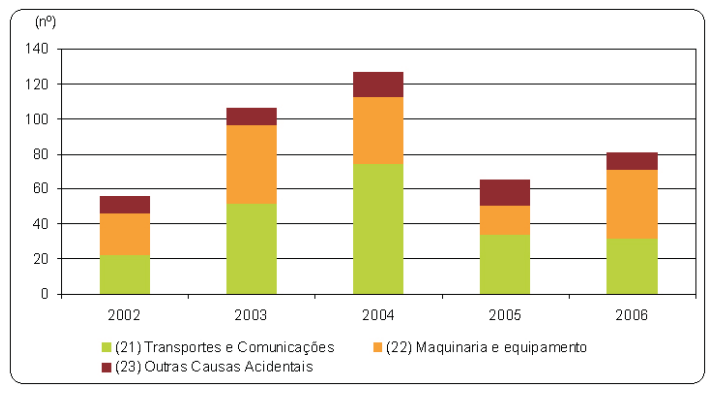

Fig. 9 - Distribuição anual dos incêndios florestais investigados, por grupos.

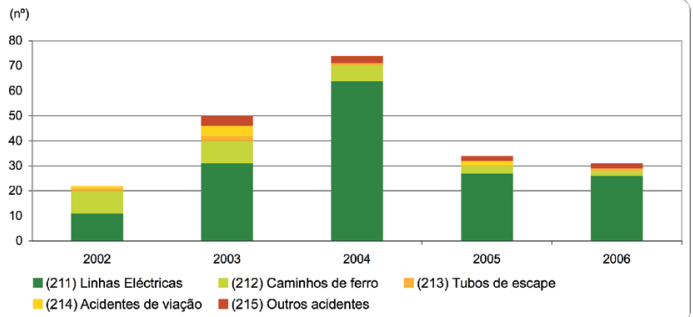

Fig. 10 - Distribuição anual dos incêndios florestais investigados, por subgrupos.

Devem ser mencionados os incêndios florestais que, apesar de terem o seu início junto às linhas férreas, possuem uma origem relacionada com actos de vandalismo ou de outra natureza não negligente, como por exemplo, actos de bruxaria realizados sobre as travessas da linha, respectivamente enquadráveis na categoria 1 - Uso do fogo, grupo 18 - Outros usos do fogo, subgrupo Causas exotéricas - 181. Convém assinalar que, segundo os autos de noticia (GNR/SEPNA), foram identificadas algumas situações na linha do Algarve associadas a práticas de bruxaria e queimadas/vandalismo das travessas, nas imediações de apeadeiros.

\section{Análise das causas e dos locais de ignição}

As áreas de maior risco podem ser definidas com base no número das ocorrências e nos quantitativos de área ardida, método pelo qual é possível determinar as linhas mais críticas e, nestas, os sectores (pontos quilométricos - PK's) mais problemáticos.

Deste modo, na Linha do Alentejo a ratio área ardida/ número de ocorrências foi considerada muito elevada, uma vez que em duas ocorrências, registadas em 2003, os valores de área total ardida foram muito superiores face à média nacional.

Em contrapartida, quando consideramos a ratio número de comboios que provocaram ignições/número de ocorrências, verificamos que a Linha da Beira Alta apresentou a média mais elevada a nível nacional, assumindo uma posição de destaque face às restantes, apresentando o maior número de ignições, 38 ocorrências (QUADRO I) e de focos por circulação ferroviária. Os 9 focos de ignição registados entre os PK's 175, 3 e 169,6, no ano de 2006, estavam associados à circulação de um comboio de mercadorias.

\section{Distribuição das ocorrências por tipo de causa provável}

De acordo com as informações constantes nos registos, a causa acidental mais provável das ignições com origem nas linhas de caminho-de-ferro parece estar relacionada com operações de frenagem. 
Quadro I - Número de ignições na rede ferroviária

\begin{tabular}{|c|c|}
\hline Linha & Ocorrências \\
\hline Beira Alta & 38 \\
\hline Beira Baixa & 9 \\
\hline Leste & 9 \\
\hline Norte & 8 \\
\hline Douro & 5 \\
\hline Évora & 5 \\
\hline Vendas Novas & 4 \\
\hline Corgo & 3 \\
\hline Sul & 3 \\
\hline Tua & 3 \\
\hline Alentejo & 2 \\
\hline Algarve & 2 \\
\hline Ramal de Tomar & 2 \\
\hline Sines & 2 \\
\hline Minho & 1 \\
\hline Ramal de Cáceres & 1 \\
\hline
\end{tabular}

Existem, ainda, outras situações que estiveram associadas a falhas mecânicas uma vez que existem relatos de ignições que, aparentemente, não estiveram ligadas às manobras de frenagem, reportando para situações de anomalias/deficiências técnicas, designadamente em termos de bloqueio de parte do sistema de frenagem.

No período compreendido entre 2003 e 2008, verificouse a existência de registos de 7 situações que referem a presença de focos de ignição relacionados com deficiências técnicas. Na Linha da Beira Alta, nos anos de 2007 e 2008, foram registadas 5 situações de problemas técnicos, as quais estão maioritariamente relacionadas com comboios de mercadorias. Convém realçar o facto desta linha assegurar a maior parte, cerca de $2 / 3$, do transporte de mercadorias, a nivel nacional.

Relativamente aos tipos de comboios que poderão estar associados às ignições, a análise da informação disponível permitiu detectar que são os comboios de mercadorias, relações de tráfego internacional (importação e exportação) e nacional, aqueles que assumem uma posição de maior destaque, com $72 \%$ das ignições, seguidos pelos comboios Histórico (vapor) e Inter-Cidades (IC), respectivamente, com $16 \%$ e $12 \%$ das ocorrências.

Com efeito, ainda que para o ano de 2002 os autos de notícia não façam nenhuma descrição ou relato sobre as situações que originaram ignições na linha de caminho de ferro, a informação disponível no Resumo da Actividade do CNGF para o ano de 2002 aponta para a existência de focos de incêndio relacionados com uma "iniciativa de uso turístico de uma locomotiva a vapor, provocou 10 focos de incêndio ao longo da Linha do Côrgo no dia 14 de Junho e 7 focos de incêndio na Linha do Tua no dia 4 de Julho" (CNGF, 2003, p. 15).

No ano de 2003 foram registadas nove ocorrências e existe informação relativa à operacionalidade dos comboios em $35 \%$ dos autos de notícia, os quais referem anomalias técnicas no sistema de frenagem de um dos vagões e situações de libertação de faúlhas pelos cepos de freio.

Em 2004 existem 6 ocorrências registadas. No entanto, os autos apenas referem a existência de material incandescente proveniente do sistema de frenagem num dos autos, para a Linha do Sul, concelho de Odemira.

Para o ano de 2005 não existe nenhum relato sobre situações que tenham originado ignições em linhas de caminho-de-ferro.

No ano de 2006, existem apenas quatro autos de notícia, com três deles a reportar para a circulação de comboios de mercadorias. Destas três situações, duas referem-se à Linha da Beira Alta e estão relacionadas com a libertação de materiais incandescente pelo comboio.

Em 2007, são 11 os autos de notícia com referência a situações decorrentes da circulação de comboios. No entanto, apenas 50\% fazem menção à libertação de partículas do sistema de frenagem. A existência de vestígios é referida em duas situações, na Linha da Beira Alta, e, numa terceira, na Linha de Évora. No conjunto das ignições registadas durante esse ano, três delas estiveram relacionadas com o sistema de frenagem em vagões de mercadorias ("cepo do freio do vagão") e, duas, com a circulação do comboio turístico a vapor, na Linha do Douro.

No ano de 2008 existem 18 autos de notícia, dos quais apenas 33,5\% fazem referência a situações relacionadas com a libertação de fragmentos metálicos. Nesse conjunto existem provas em metade das situações referenciadas, estando duas delas relacionadas com a circulação do comboio histórico.

Em 2008, a circulação regular de máquinas a vapor, no âmbito da campanha dos Comboios Históricos do Douro, promovida pela $\mathrm{CP}$, estava prevista entre os meses de Maio e Outubro. Consciente das situações de risco de ignição relacionadas com este tipo de tráfego, a CP estabeleceu, a exemplo do triénio anterior, um protocolo com a Associação Humanitária de Bombeiros Voluntários de Peso da Régua, com o objectivo precaver eventuais ocorrências (CP/REFER, 2007 e 2008). Além disso, a utilização de tracção a vapor esteve sempre condicionada às condições atmosféricas, que se fizessem sentir em cada dia.

\section{Distribuição das ocorrências por severidade dos danos}

Ainda que se desconheça a área ardida em algumas das ocorrências, a análise dos valores apurados permitiu identificar as linhas mais problemáticas em termos de primeira intervenção, e que, por conseguinte, provocaram maiores áreas ardidas. 
As que apresentaram mais área ardida relacionada com a causa 212 foram as da Beira Alta, Alentejo, com mais de 1000 ha cada, seguidas pela do Leste, com pouco mais de 250 ha, e pela do Corgo e Ramal de Cáceres, cada uma com mais de 100 hectares (QUADRo II).

Todavia, se considerarmos a área média ardida por ocorrência, o posicionamento passa a ser diferente, com a Linha do Alentejo a ocupar a primeira posição, com mais de 500 ha por ocorrência, seguida do Ramal de Cáceres, com mais de 100 ha por incêndio, o que pode significar alguma dificuldade sentida nesta região em controlar a propagação de focos de incêndio, cuja evolução originou incêndios.

O segundo conjunto, em que a média de área ardida se situou entre 25 e 50 ha por ocorrência, agrupa as linhas do Corgo, Beira Alta e Leste, às quais corresponde uma área ardida significativa, distribuída por diversas ocorrências. A rondar os 25 ha está também a linha de Sines com menor número de ignições face às anteriores (Quadro II).

Quadro II - Área ardida (ha), ordenada por ordem alfabética de via férrea e pelo número decrescente de área ardida e de área média ardida por ocorrência

\begin{tabular}{|c|c|c|c|c|c|c|}
\hline \multirow{2}{*}{ Linha } & \multicolumn{2}{|c|}{ Área ardida } & \multirow{2}{*}{ Linha } & \multirow{2}{*}{$\begin{array}{l}\text { Área } \\
\text { ardida }\end{array}$} & \multirow{2}{*}{ Linha } & \multirow{2}{*}{$\begin{array}{l}\text { Área } \\
\text { média }\end{array}$} \\
\hline & Total & Média & & & & \\
\hline Alentejo & 1013 & 506,5 & Beira Alta & 1499,07 & Alentejo & 506,5 \\
\hline Algarve & 2,11 & 1,05 & Alentejo & 1013 & $\begin{array}{l}\text { Ramal de } \\
\text { Cáceres }\end{array}$ & 110 \\
\hline Beira Alta & 1499,07 & 39,45 & Leste & 263,86 & Corgo & 47,82 \\
\hline Beira Baixa & 36,37 & 4,04 & Corgo & 143,47 & Beira Alta & 39,45 \\
\hline Corgo & 143,47 & 47,82 & $\begin{array}{l}\text { Ramal de } \\
\text { Cáceres }\end{array}$ & 110 & Leste & 29,31 \\
\hline Douro & 24,28 & 4,85 & Sines & 49 & Sines & 24,5 \\
\hline Évora & 35,03 & 7,01 & Beira Baixa & 36,37 & Douro & 8,09 \\
\hline Leste & 263,86 & 29,31 & Évora & 35,03 & Évora & 7,01 \\
\hline Minho & 0 & 0 & Norte & 34,68 & Norte & 4,34 \\
\hline Norte & 34,68 & 4,34 & Douro & 24,28 & Beira Baixa & 4,04 \\
\hline $\begin{array}{l}\text { Ramal de } \\
\text { Cáceres }\end{array}$ & 110 & 110 & Vendas Novas & 9,32 & Vendas Novas & 2,33 \\
\hline Ramal de Tomar & 0 & $s / d$ & Algarve & 2,11 & Sul & 1,5 \\
\hline Sintra & 0 & 0 & Tua & 1,59 & Algarve & 1,05 \\
\hline Sines & 49 & 24,5 & Sul & 1,5 & Tua & 0,53 \\
\hline Sul & 1,5 & 0,5 & Minho & 0 & Minho & 0 \\
\hline Tua & 1,59 & 0,53 & Sintra & 0 & Sintra & 0 \\
\hline Vendas Novas & 9,32 & 2,33 & Ramal de Tomar & $s / d$ & Ramal de Tomar & $s / d$ \\
\hline
\end{tabular}

\section{Distribuição das ocorrências por classes de velocidade e cargas máximas das vias}

As linhas de caminho-de-ferro portuguesas estão divididas, segundo o Directório da Rede 2008 (REFER, 2007), em 5 classes de velocidade. Se considerarmos o número de ocorrências em função da velocidade predefinida, verificamos que as linhas cuja velocidade varia entre $120 \mathrm{~km} / \mathrm{h}$ e $160 \mathrm{~km} / \mathrm{h}$ foram as que representam o maior número de ocorrências, 48 no conjunto, ou seja, 50\% do total. De entre as linhas que estão nestas condições, destaca-se a da Beira Alta, que detém 79\% das ignições (Fig.11).

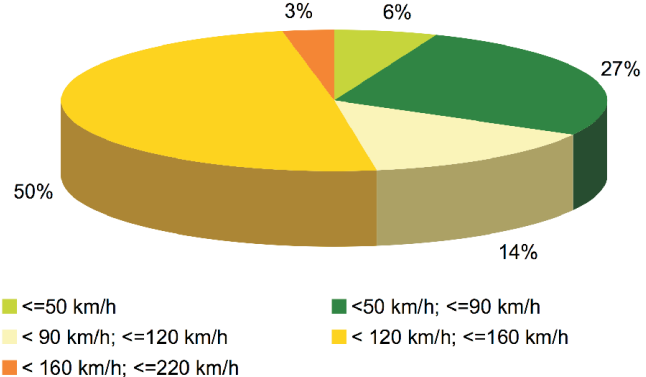

Fig. 11 - Distribuição das ocorrências, entre 2002 e 2008, por patamar de velocidade.

As linhas cuja velocidade permitida está compreendida entre $\quad<=50 \mathrm{~km} / \mathrm{h}$ e $\quad<=90 \mathrm{~km} / \mathrm{h}$ registaram, respectivamente, 6 e 26 ignições, que no conjunto correspondem a $32,9 \%$ do total das ocorrências. De entre estas linhas, destacam-se as do Douro, Tua e Corgo, com $37,5 \%$ das ignições.

Parece, pois, existir uma certa relação de causa-efeito entre a velocidade das linhas e o número de ocorrências, pelo menos na Linha da Beira Alta, mas, atendendo a que a velocidade máxima dos comboios de mercadorias é de $100 \mathrm{~km} / \mathrm{h}$, tal facto não será tão relevante, pelo menos em relação a este tipo de comboios.

Por outro lado, as curvas das linhas são dotadas de escala adequada, ou seja, a inclinação do plano de rolamento para o interior das curvas, a qual permite que, por regra, os comboios não necessitem de frenar à entrada das curvas. Exceptua-se o caso dos troços em pendente, como é o caso da Linha da Beira Alta, no sentido de Vilar Formoso para Pampilhosa, nos quais efectivamente os maquinistas têm que controlar a velocidade do comboio pela aplicação da frenagem.

As características dos troços das linhas nos quais foram registados focos de incêndio estão, geralmente, associadas a sectores sinuosos. Verificou-se que cerca de $78 \%$ das ocorrências estão localizadas em secções curvas ou nas proximidades de curvas, indicando que as manobras de desaceleração e frenagem podem, de algum modo, estar relacionadas com a presença de focos de ignição.

De acordo com o Directório da Rede 2009 (REFER, 2008), onde é apresentado o mapa com as cargas máximas admissíveis, na ficha UIC 700-0 (Quadro III), parece existir, para o conjunto de ignições registadas, uma certa relação entre o número de ignições e a carga máxima passível de ser transportada. A classificação D4 é utilizada, por exemplo, na Linha da Beira Alta, que representou quase metade do número total de o corrências registadas entre 2002 e 2008. 


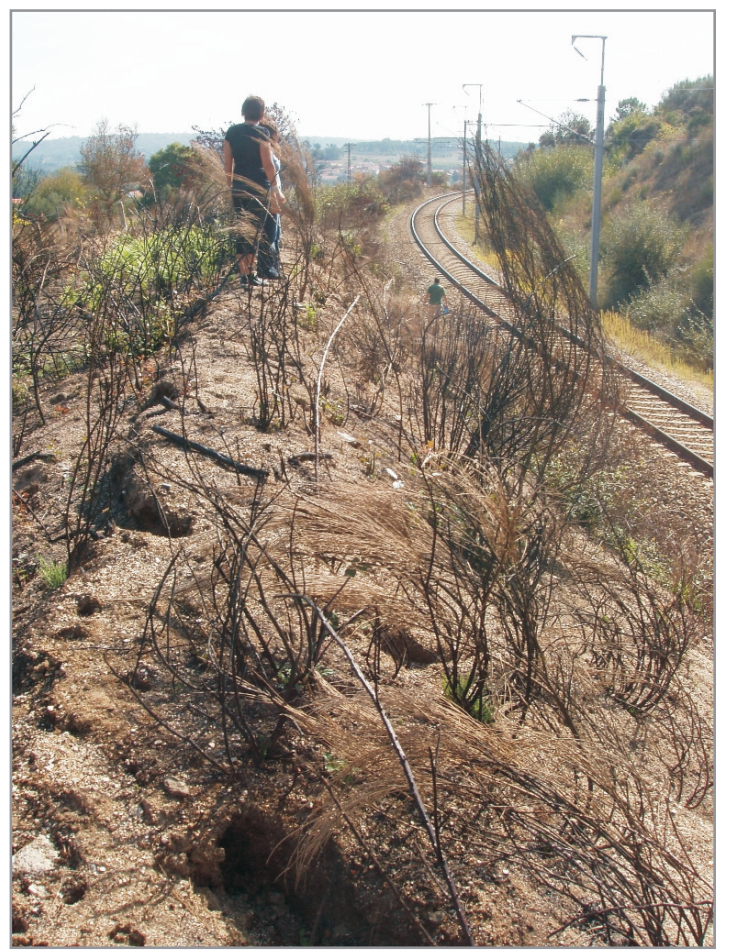

pk 184 - A - Sentido V. F. Naves - Guarda;

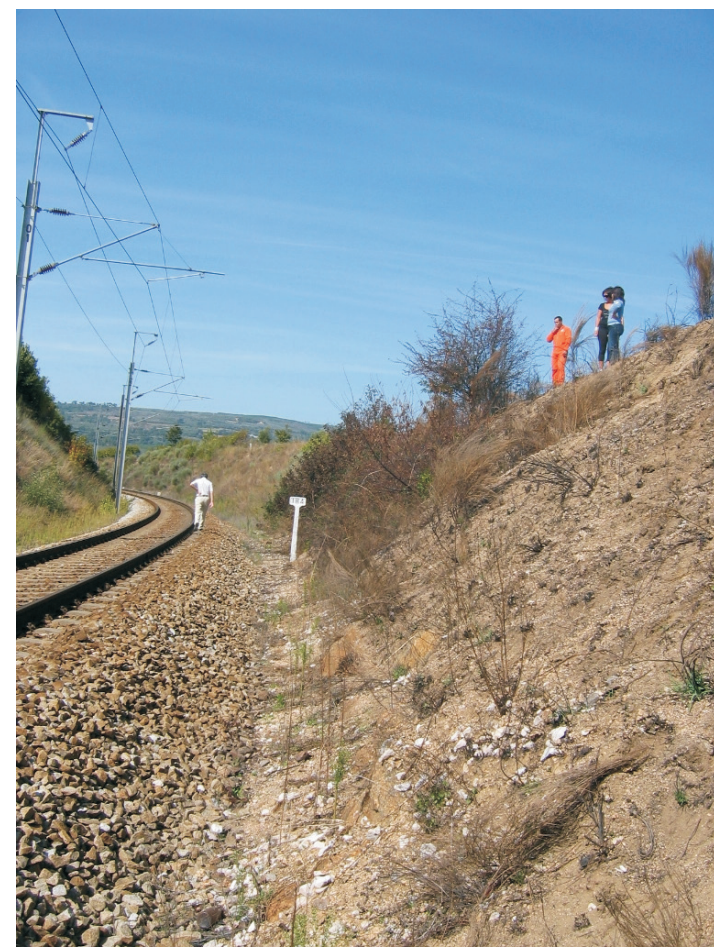

pk 184 - B - Sentido Guarda - V. F. Naves.

Fig. 12 - Detalhes de áreas ardidas junto a sectores curvos da via férrea.

QUADRo III - Classificação das cargas máximas admissíveis nas Linhas de Via Larga

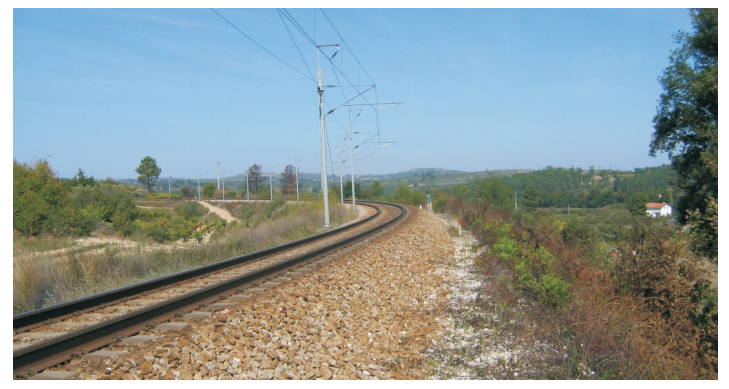

pk 185 - sentido Guarda - V. F. das Naves.

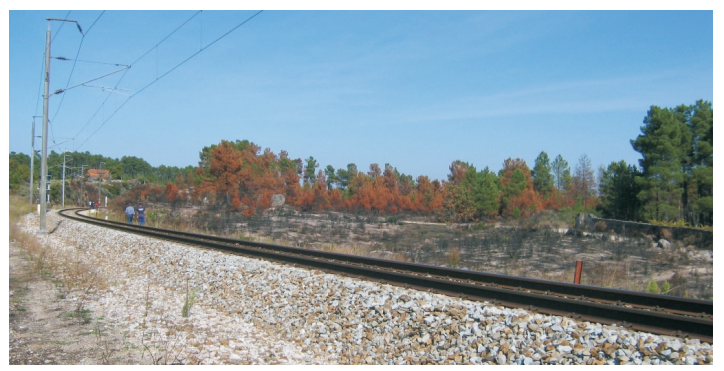

pk 187,7 - sentido Guarda - V. F. das Naves.

Fig. 13 - Aspectos de áreas ardidas junto a sectores curvos da via férrea.

\begin{tabular}{|l|c|c|c|}
\hline Classificação & \multicolumn{1}{c}{ T/Eixo } & \multicolumn{1}{c|}{ T/m } & Ocorrências (\%) \\
\hline D4 & 22,5 & 8 & 76,9 \\
\hline D2 & 22,5 & 6,4 & 8,8 \\
\hline C4 & 20 & 8 & 1,1 \\
\hline B1 & 18 & 5 & 7,7 \\
\hline A & 16 & 5 & 5,5 \\
\hline
\end{tabular}

Fonte: REFER, 2008 (adaptado).

\section{Conclusões}

Tendo como base a investigação realizada, que se fundamentou na pesquisa dos registos, na análise estatística, na consulta bibliográfica, no trabalho de campo, na partilha de informações e no saber e conhecimento das várias equipas técnicas, afigura-se-nos um conjunto de aspectos que permitiram contextualizar a ocorrência de ignições e, consequentemente, dos incêndios florestais com origem nas linhas de caminhode-ferro e no material circulante.

Com base nos diversos elementos disponíveis pode concluir-se que as áreas percorridas pelos incêndios florestais com provável origem nas linhas de caminho-deferro, se ficaram a dever à concorrência de um conjunto de factores. De entre eles, podemos mencionar aqueles que se prendem com as características da via e com os sistemas de frenagem do material circulante, como 
outros que se devem às características dos combustíveis finos que ladeiam as vias, e às condições atmosféricas que se fazem sentir no momento da ignição.

Embora as situações meteorológicas, em certos dias, tenham assumido alguma gravidade, não podem, no entanto, ser as únicas, nem sequer as principais responsáveis pelas áreas queimadas. Com efeito, várias circunstâncias concorreram para que se tivesse verificado um certo número de ocorrências de incêndios florestais com origem nas linhas de caminho-de-ferro que levaram à mobilização de meios de combate.

De entre elas e para cada um dos parâmetros mencionados, cabe destacar as seguintes:

\section{Causalidade:}

A maioria das causas prováveis imputadas à via férrea tem a ver com ignições originadas pela emissão de fragmentos incandescentes, faíscas e transmissão de calor decorrente de diversas actividades ferroviárias, designadamente a problemas relacionados com o sistema de frenagem do material circulante ou com a realização de trabalhos na via;

A causa acidental mais provável das ignições com origem nas linhas de caminho-de-ferro parece estar relacionada com operações de frenagem (cepos de ferro);

Ocasionalmente, durante as operações de frenagem, podem libertar-se e ser projectados fragmentos metálicos, incandescentes (sujeitos a condições de stress mecânico e térmico) e desencadear a ignição de combustíveis finos e secos e, consequente, propagação.

\section{Distribuição geográfica:}

O distrito da Guarda foi aquele que, no período em estudo, registou o maior número de ocorrências e a maior área ardida;

O sector mais crítico da Linha da Beira Alta, face à reincidência de ignições na mesma área, parece estar também relacionado com as características sinuosas da linha e as implicações que daí resultam em termos da operacionalidade das composições;

Só na Linha da Beira Alta, e apenas nos anos de 2007 e 2008, existem 5 situações registadas com problemas técnicos, as quais estão maioritariamente relacionadas com a circulação de comboios de mercadorias.

\section{Velocidade:}

Existe uma aparente relação de causa-efeito entre a velocidade permitida nas linhas e o número de ocorrências;
Parece existir um certo paralelismo, pelo menos na Linha da Beira Alta, entre velocidade dos comboios, operações de frenagem e ignições motivadas pela circulação ferroviária;

As linhas cuja velocidade permitida está compreendida entre $120 \mathrm{~km} / \mathrm{h}$ e $160 \mathrm{~km} / \mathrm{h}$ são aquelas que apresentam o maior número de ocorrências, 48 no conjunto, ou seja, $50 \%$ do total. De entre elas, destaca-se a da Beira Alta, que detém $79 \%$ destas ignições. Contudo, não se pode estabelecer uma relação directa entre velocidade permitida e número de ignições, uma vez que estas poderão estar mais relacionadas com o facto das linhas possuírem declives acentuados, por atravessarem áreas montanhosas ou plataformas inclinadas, e, por conseguinte, à aplicação quase em contínuo dos freios dos comboios, quando estes circulam no sentido descendente.

\section{Geometria da via:}

Mais de $75 \%$ das ocorrências localizam-se em sectores curvos ou na sua aproximação, indicando que as manobras de desaceleração e frenagem podem, de algum modo, estar relacionadas com a presença de focos de ignição, facto que foi confirmado pelo trabalho de campo;

O trabalho de campo demonstrou, ainda, que a maioria das ignições tende a ocorrer nos sectores curvos ou nas rectas de aproximação a curvas, onde se desenvolvem maiores condições de stress mecânico, motivadas por acções de desaceleração e de redução de velocidade, designadamente com a utilização dos freios;Prevenção:

É essencial criar mecanismos que permitam a remoção/ redução do estrato herbáceo na banqueta (patamar de suporte ao balastro em que assenta a via), até uma distância de pelo menos $2 \mathrm{~m}$ para cada um dos lados, e proceder à gestão dos estratos arbustivo e arbóreo, a partir desta faixa e até ao limite de propriedade da REFER, demarcado pela vedação, quando existe.

\section{Referências bibliográficas}

AFNDF, Autoridade Florestal Nacional Defesa da Floresta (2008) - Relatório Provisório Fases Alfa, BravoCharlie e Delta, Autoridade Florestal Nacional, Lisboa, 17 p.;

BEIGLEY, Mark e QuinsenBERRY, Michael (USDA Forest Service) (2005) “Observações e Recomendações”, Relatório do Projecto de Cooperação Técnica Incêndios Florestais em Portugal. apresentado no Seminário realizada na FLAD em Fevereiro de 2004 e publicado nas respectivas Actas: Prevenção, Deteç̧ão e Combate de Fogos Florestais, Fundação Luso-Americana, Lisboa, 208 p. 
Carvalho, Josefa Buxo de (2003) - Codificação e definição das categorias das causas dos incêndios florestais. Divisão de Protecção e Conservação Florestal, DGF, Lisboa, 9 p.;

CNGF, Corpo Nacional da Guarda Florestal (2003) - Fogos Florestais. Resumo da actividade em 2002, Direcção-Geral das Florestas, Lisboa, 34 p.;

CP/REFER, Comboios de Portugal, EP e Rede Ferroviária Nacional, EPE (2005) - “A. Caracterização da problemática dos incêndios florestais, em 2005". Incêndios Florestais, Relatório - 2005, p. 5-8 (inédito);

CP/REFER, Comboios de Portugal, EP e Rede Ferroviária Nacional, EPE (2006) - “4. Evolução anual das ocorrências de incêndio”. Incêndios Florestais, Relatório - 2006, p. 5-8 (inédito);

CP/REFER, Comboios de Portugal, EP e Rede Ferroviária Nacional, EPE (2007) - “4. Evolução anual das ocorrências de incêndio”. Incêndios Florestais, Relatório - 2007, p. 14-23 (inédito);

CP/REFER, Comboios de Portugal, EP e Rede Ferroviária Nacional, EPE (2008) - Plano Ferroviário de Defesa da Floresta Contra Incêndios 24 p. (inédito);

CRIF - Cartografia de Risco de Incêndio Florestal, http:/ / www.scrif.igeo.pt/cartografiacrif/cartogra. htm

DFCl, Defesa da Floresta contra Incêndios (2008) Relatório Anual de Incêndios Florestais, 2007, Direcção-Geral dos Recursos Florestais, Lisboa, 44 p.;

DFFP, Department of Forestry and Fire Protection State of California (1999) - Railroad Fire Prevention, Field Guide, 109 p.;

DSDF, Divisão de Defesa da Floresta contra Incêndios (2006) - Incêndios Florestais - Relatório de
2005, Direcção-Geral dos Recursos Florestais, Lisboa, 26 p.;

Freire, Sérgio; Carrão, Hugo e Caetano, Mário R. - Produção de Cartografia de Risco de Incêndio Florestal com Recurso a Imagens de Satélite e Dados Auxiliares, 15 p., http://www.igeo.pt/gdr/ pdf/Freire2002.pdf

Lourenço, Luciano (2006a) - “Incêndios Florestais. Algumas reflexões sobre prevenção e mitos do combate", Territorium, 13, Riscos - Associação Portuguesa de Riscos, Prevenção e Segurança, Coimbra, p. 59-70 http: //www.nicif.pt/riscos/ Territorium13.htm;

Lourenço, Luciano (Coord.) et al. (2005) - Plano Nacional de Defesa da Floresta contra Incêndios, Agência para a Prevenção de Incêndios Florestais, Miranda do Corvo, II vol. (236+387 p.);

Lourenço, Luciano e Rainha, Manuel (2006) - “As mediáticas 'mãos criminosas de incendiários' e algumas das 'lições dos fogos florestais de 2005', em álbum fotográfico. Contributo para a desmistificação dos incêndios florestais em Portugal", Territorium, 13, Riscos, Coimbra, p. 71-82 http://www.nicif.pt/riscos/ Territorium13.htm;

REFER (2007) - Directório da Rede 2008, e 1. ${ }^{a}$ Adenda ao Directório da Rede 2008 http://www. refer.pt/Documentos/1a\%20Adenda\%20ao\%20 Directório\%20da\%20Rede\%202008.pdf

REFER (2009) - Directório da Rede 2009, http: / / www.refer. pt/Documentos/Directorio_da_Rede_2009. pdf;

Verde, J. e Zêzere, J. L. (2005) - “Avaliação da perigosidade de incêndio florestal", Actas do VI Congresso da Geografia Portuguesa, Lisboa, 23 p. (no prelo). 